\title{
Energia Metabolizável e Lisina Digestível para Suínos na Fase de Crescimento, Criados em Condições de Segregação Sanitária ${ }^{1}$
}

\author{
Messias Alves da Trindade Neto2*, José Aparecido Moreira ${ }^{3}$, Dirlei Antônio Berto ${ }^{4}$, Ricardo \\ Albuquerque $^{2}$, Eliana Aparecida Schammass ${ }^{5}$
}

\begin{abstract}
RESUMO - Em dois ensaios simultâneos avaliou-se níveis de energia metabolizável (EM) e de lisina digestível (LIS) para suínos de linhagem específica, na fase de crescimento, criados em condições de isolamento sanitário. Foram utilizados 72 machos castrados com $23,34 \pm 1,62 \mathrm{~kg}$ e 72 marrãs com 21,56 $\pm 2,86 \mathrm{~kg}$. O delineamento experimental foi em blocos casualizados, em esquema fatorial 2 x 3 , com seis repetições e dois animais por unidade experimental. Os tratamentos decorreram da combinação dos fatores EM (3.270 e 3.500 $\mathrm{kcal} / \mathrm{kg}$ de ração) e LIS $(0,83 ; 1,03$ e 1,23\%). Não houve interação dos fatores, mas foram constatados efeitos principais de EM e LIS sobre as variáveis de desempenho. Os machos castrados apresentaram respostas diferenciadas aos níveis crescentes de lisina dietética, com aumento linear no ganho em peso, enquanto no consumo de ração e na conversão alimentar ocorreu respostas quadráticas. As marrãs apresentaram redução linear na conversão alimentar em resposta à elevação da concentração de lisina na dieta. Criados com separação de sexo e em condições desejáveis de saúde, na fase de crescimento, suínos machos castrados e marrãs da linhagem genética estudada, responderam eficientemente ao acréscimo de lisina digestível nas dietas. Os benefícios dietéticos da lisina no desempenho dos machos castrados não dependeram dos níveis estudados de energia. Nas marrãs, a melhor conversão alimentar foi obtida com dietas de 3.500 kcal EM, caracterizando a maior eficiência na utilização dos nutrientes para as necessidades de desempenho, em comparação aos machos castrados.
\end{abstract}

Palavras-chave: conversão alimentar, ganho de peso, machos castrados, marrãs

\section{Metabolizable Energy and Digestible Lysine for Pigs in the Growing Fhase on Sanitary Segregation Conditions}

\begin{abstract}
Two assays run simultaneously to evaluate the levels of metabolizable energy (ME) and digestible lysine (LYS) for growing pigs from specific strain on sanitary isolation conditions. Seventy-two castrated males averaging $23.34 \pm 1.62 \mathrm{~kg}$ and 72 gilts averaging $21.56 \pm 2.86 \mathrm{~kg}$ were assigned to a randomized blocks design with a $2 \mathrm{x} 3$ factorial arrangement and six replications of two animals per experimental unit. The treatments consisted of the combination of energy $(3,270$ and 3,500 kcal of ME/kg) and lysine levels $(0.83,1.03$, and $1.23 \%$ digestible). No interaction of energy x protein levels was observed, although effects of the main factors on performance variables were detected. Castrated males showed linear increase of weight gain and quadractic of feed intake and feed:gain ratio, as the dietary lysine levels increased. Linear decrease on feed: gain ratio in response to the dietary lysine concentration was noticed for gilts. Castrated males and gilts in the growing phase on sanitary isolation conditions and healthy conditions showed positive response to the dietary digestible lysine increase. Effects of dietary lysine levels on performance of castrated males did not depend on the energy levels. Gilts fed diets with 3,500 kcal of ME/kg showed the best feed:gain ratio, that confirmed the greatest results of nutrient efficiency utilization in relation to the castrated males.
\end{abstract}

Key Words: feed: gain ratio, weight gain, barrows, gilts

\section{Introdução}

Diferentemente de climas frios, em condições de temperaturas mais elevadas, o suíno necessita de menor produção interna de calor para manter a temperatura corporal constante. Nessas condições, o animal reduz o consumo para minimizar a produção de calor metabólico e evitar o estresse térmico proveniente do incremento calórico da dieta que se torna prejudicial. Em ambas as condições de temperatura, o suíno necessitará de dietas que propiciem diferentes incrementos calóricos (Patience et al., 1995). É sabido que a dieta rica em fibra produz alto incremento calórico, enquanto a rica em óleos ou gordura permite maior ingestão de energia com menor incremento calórico, uma vez que o processo de digestão é mais eficiente e permite maior assimilação dos nutrientes afins.

\footnotetext{
1 Trabalho realizado com o apoio da Ajinomoto Biolatina Indústria e Comércio Ltda e FAPESP.

2 Professor Doutor do Departamento de Nutrição e Produção Animal da FMVZ-USP, Campus de Pirassununga, Rua Duque de Caxias Norte, 225, CEP 13635-900 - Pirassununga - SP (messiasn@usp.br).

3 Biólogo, Dr.

${ }^{4}$ Professor Doutor do Departamento de Produção e Exploração Animal, FMVZ, UNESP/Botucatu, SP.

${ }^{5}$ Pesquisadora do Instituto de Zootecnia - Rua Heitor Penteado 56, Nova Odessa, SP, CEP 13460-000.
} 
Conhecidas as características energéticas dos alimentos, a determinação da fração metabolizável e líquida de energia da dieta torna-se um referencial na elaboração de dietas para suínos sob diferentes condições climáticas, visto a necessidade de se controlar a ingestão de energia e de nutrientes, necessários às demandas de manutenção e produção. No caso do suíno em fase de crescimento, segundo Ewan (1991), a eficiência de utilização da energia é determinada pela deposição de gordura e proteína no ganho, de modo que o custo para deposição de um grama de proteína seria de $1,12 \mathrm{kcal}$, enquanto, para a mesma quantidade de gordura, seria de 7,83 kcal. Assim, a deposição de gordura exigiria mais energia que proteína por unidade de tecido ganho e a necessidade de energia por unidade de ganho aumentaria durante o período de crescimento.

Por outro lado, as demandas nutricionais para o crescimento no decorrer do desenvolvimento dependem das condições fisiológicas do suíno. Como ocorre na utilização da energia nos processos metabólicos, sua distribuição para os tecidos é determinada pela fisiologia que regula e adapta o animal às situações do ambiente (Claus \& Weiler, 1994). Entre os fatores não atribuídos ao genótipo, as condições sanitárias têm grande importância na eficiência de utilização dos nutrientes pelo suíno. Expostos a organismos patogênicos, os suínos podem ter uma redução de $10 \mathrm{a}$ $40 \%$ na eficiência do ganho muscular, correspondendo entre 5 e $20 \%$ do rendimento na carcaça (Stahley, 1993). Em condições sanitárias desejáveis, os nutrientes são melhor utilizados, permitindo maior expressão do desempenho suíno (Affentranger et al., 1996; Kolstad \& Vanger, 1996). Segundo Williams et al. (1997b), a exposição dos suínos a antígenos, patogênicos ou não, desencadeia a liberação de substâncias que ativam o sistema imunológico, alterando o processo metabólico em detrimento à síntese protéica na musculatura esquelética. Em animais com títulos para diversos anticorpos, a citoquina mediaria alterações na síntese e degradação protéica muscular, inibindo a liberação de hormônios anabólicos, como a somatotropina e o fator semelhante à insulina IGF-I (Williams et al., 1997a,b).

Segundo Fuller \& Wang (1990) e Chavez (1996), na determinação das exigências dos aminoácidos, a variação na síntese protéica, ocorrida em função do peso corporal, teria relação com o uso da energia, devendo ser considerada em programas de alimentação multifásica e nas metas, para redução da excreção de nitrogênio (Van Lunen \& Cole 1996; Dourmad et al., 1996). Em condições de ambiente desejáveis, todavia, as exigências de aminoácidos e a síntese protéica no suíno sofrem influência de raça e sexo, além do peso vivo (Friesen et al. 1994; Ettle et al., 2003). Entre os fatores que afetam a utilização de lisina pelo suíno, segundo Susenbeth (1995), o nível de ingestão, a ingestão de energia, de aminoácidos essenciais, da soma de aminoácidos não essenciais e o potencial de crescimento dos animais são influenciados pelo genótipo e pelo ambiente.

O sexo exerce efeito sobre a taxa de deposição do nitrogênio e, em ordem decrescente, esta eficiência seria: machos inteiros, fêmeas e machos castrados. Esta seqüência é bastante considerada em outros países quando da elaboração de dietas e otimização da nutrição de suínos em crescimento e terminação (Cromwell et al., 1993; Batterham et al., 1994; Quiniou et al., 1996; Webb, 2003; De Abreu, 2004).

Segundo Ekstrom (1991), a criação de suínos com separação de sexos deve ser vista como estratégia, considerando-se as diferenças de exigências nutricionais a que lhes são atribuídas. Sabe-se que as respostas para desempenho e qualidade de carcaça diferem entre machos castrados e fêmeas, em decorrência das variações dos níveis nutricionais exigidos (Ekstrom, 1991). De acordo com o autor, machos castrados consomem mais alimentos e têm maior ganho em peso. Ao mesmo tempo, as fêmeas ingerem menos alimentos e são mais eficientes na deposição de carne na carcaça (comparadas a machos castrados), embora suas exigências em aminoácidos possam ser maiores. Segundo Susenbeth (1995), além dos fatores limitantes da utilização de lisina pelo suíno, haveria poucas informações para efeito do sexo.

Além dos aspectos de produtividade, o mercado consumidor tornou-se uma das diretrizes nas ações do melhoramento genético e da nutrição de suínos. Assim, a formulação de dietas com ênfase nas especificidades dos suínos comerciais existentes no mercado mundial devem ser periodicamente revistas, evitando-se níveis nutricionais abaixo ou acima dos sugeridos, cujas implicações revertem-se negativamente ao produtor e ao meio ambiente.

Em razão do exposto, avaliaram-se dois níveis de energia metabolizável e três de lisina digestível com suínos de linhagem específica, machos castrados e marrãs, criados distintamente em condições de isolamento sanitário na fase de crescimento. 


\section{Material e Métodos}

Simultaneamente, foram conduzidos dois ensaios experimentais com suínos na fase de crescimento, separados por sexo, um com machos castrados de peso inicial $23,34 \pm 1,62 \mathrm{~kg}$ e outro com fêmeas de peso inicial $21,56 \pm 2,86 \mathrm{~kg}$.

O estudo foi conduzido na Unidade Experimental do Polo Regional Centro-Sul, em Piracicaba, antiga Estação de Avaliação de Suínos da Secretaria de Agricultura do Estado de São Paulo. Unidade experimental considerada como de isolamento sanitário, para animais em crescimento e terminação, completamente isolada de outras criações e ocupada apenas no período de experimentação.

Os animais, de linhagem genética específica, eram provenientes de cruzamentos entre reprodutores e matrizes comerciais. Foram distribuídos em delineamento de blocos ao acaso, em esquema fatorial $2 \times 3$, com seis tratamentos, seis repetições e dois animais por unidade experimental. A formação dos blocos baseou-se no peso inicial dos animais. Os tratamentos decorreram da combinação de dois níveis de energia metabolizável ( 3.270 e $3.500 \mathrm{kcal} / \mathrm{kg})$ e três níveis de lisina digestível $(0,83 ; 1,03$ e $1,23 \%)$ na ração. $O$ controle experimental foi efetuado ao início e final do período experimental.

Os animais foram alojados em baias de 2,00 x 1,00 m, construídas em estrutura metálica sobre piso de cimento, contendo bebedouros do tipo chupeta e comedouros simples, no interior de um galpão de alvenaria, com pédireito de 3,50 metros, dispondo nas laterais janelas do tipo basculante para controle da ventilação. $\mathrm{O}$ acesso às instalações era restrito aos funcionários da unidade.

Na elaboração das dietas experimentais (Tabela 1), adotaram-se as referências nutricionais do NRC (1998). Alimentação e água foram fornecidas à vontade, sendo a ração armazenada em recipiente individual junto a cada baia, para ser fornecida em diversos tratos diários, de modo a não privar os animais do alimento.

As pesagens dos animais para controle do desempenho foram realizadas no início e ao final do período experimental e, após 35 dias, foram retirados da Unidade Experimental. As análises estatísticas das variáveis ganho de peso, consumo de ração e conversão alimentar foram realizadas por meio do pacote computacional SAS (1996) e as médias, comparadas pelo teste $\mathrm{F}$, conforme modelo:

$$
\mathrm{Y}_{\mathrm{ijk}}=\mathrm{m}+\mathrm{A}_{\mathrm{i}}+\mathrm{B}_{\mathrm{j}}+\mathrm{AB}_{\mathrm{ij}}+\mathrm{C}_{\mathrm{k}}+\mathrm{e}_{\mathrm{ijk}} \text {, }
$$

em que $\mathrm{Y}_{\mathrm{ijk}}$ : constante associada a todas observações; $\mathrm{m}$ : média geral da variável; $\mathrm{A}_{\mathrm{i}}$ : efeito do nível de energia $i$, sendo $i=1$ e $2 ; B_{j}$ : efeito do nível de lisina $\mathrm{j}$, sendo $\mathrm{j}=1,2$ e $3 ; \mathrm{AB}_{\mathrm{ij}}$ : efeito da interação dos fatores i e j; $\mathrm{C}_{\mathrm{k}}$ : efeito do bloco $\mathrm{k}$, sendo $\mathrm{k}=1,2, \ldots$ e $6 ; \mathrm{eij}_{\mathrm{k}}=$ erro aleatório associado a cada observação.

Uma vez não observada interação dos fatores, aplicou-se a regressão polinomial para os níveis de lisina e o teste $\mathrm{F}$, para os níveis de energia.

A determinação da margem bruta rsultante da alimentação ocorreu segundo Guidoni et al. (1997), em que: Margem bruta $=($ peso ao final do período de avaliação $\times \mathrm{R} \$ / \mathrm{kg}$ do suíno) - (Consumo de ração total x R $\$ / \mathrm{kg}$ ração) - (peso inicial x $\mathrm{R} \$ / \mathrm{kg}$ do suíno). Nesta avaliação, o preço por quilo ao início da avaliação (saída de creche) foi estabelecido em 10\% do preço da arroba suína.

\section{Resultados e Discussão}

Considerando as variáveis de desempenho, em nenhum dos ensaios foi observada interação $(\mathrm{P}>0,10)$ entre o nível de energia metabolizável e de lisina digestível. Para essas variáveis, ocorreram efeitos isolados dos principais fatores. Por outro lado, ao transformar o consumo de ração em ingestão de energia e lisina, observaram-se algumas interações dos fatores principais.

Os resultados de desempenho aferidos na avaliação com machos castrados (Tabela 2), mostram efeito do fator nível de lisina digestível. Os animais apresentaram ganho de peso, consumo de ração e conversão alimentar diferenciados em resposta aos níveis crescentes de lisina nas rações experimentais. O ganho de peso aumentou $(\mathrm{P}<0,05)$ linearmente. No consumo de ração $(\mathrm{P}<0,01)$ e na conversão alimentar $(\mathrm{P}<0,06)$, houve respostas quadráticas em relação ao nível de lisina digestível, indicando como nível ótimo de lisina digestível 1,015\%, conforme equações apresentadas na Tabela 3. Em relação às concentrações da energia dietética, comparadas pelo teste F, não houve diferenças significativas entre as médias dessas mesmas variáveis.

As respostas para ganho de peso diário e conversão alimentar evidenciaram maior eficiência na utilização dos nutrientes com o aumento da concentração 
Tabela 1 - Composição centesimal das dietas experimentais Table 1 - Ingredient composition (\%) of the experimental diets

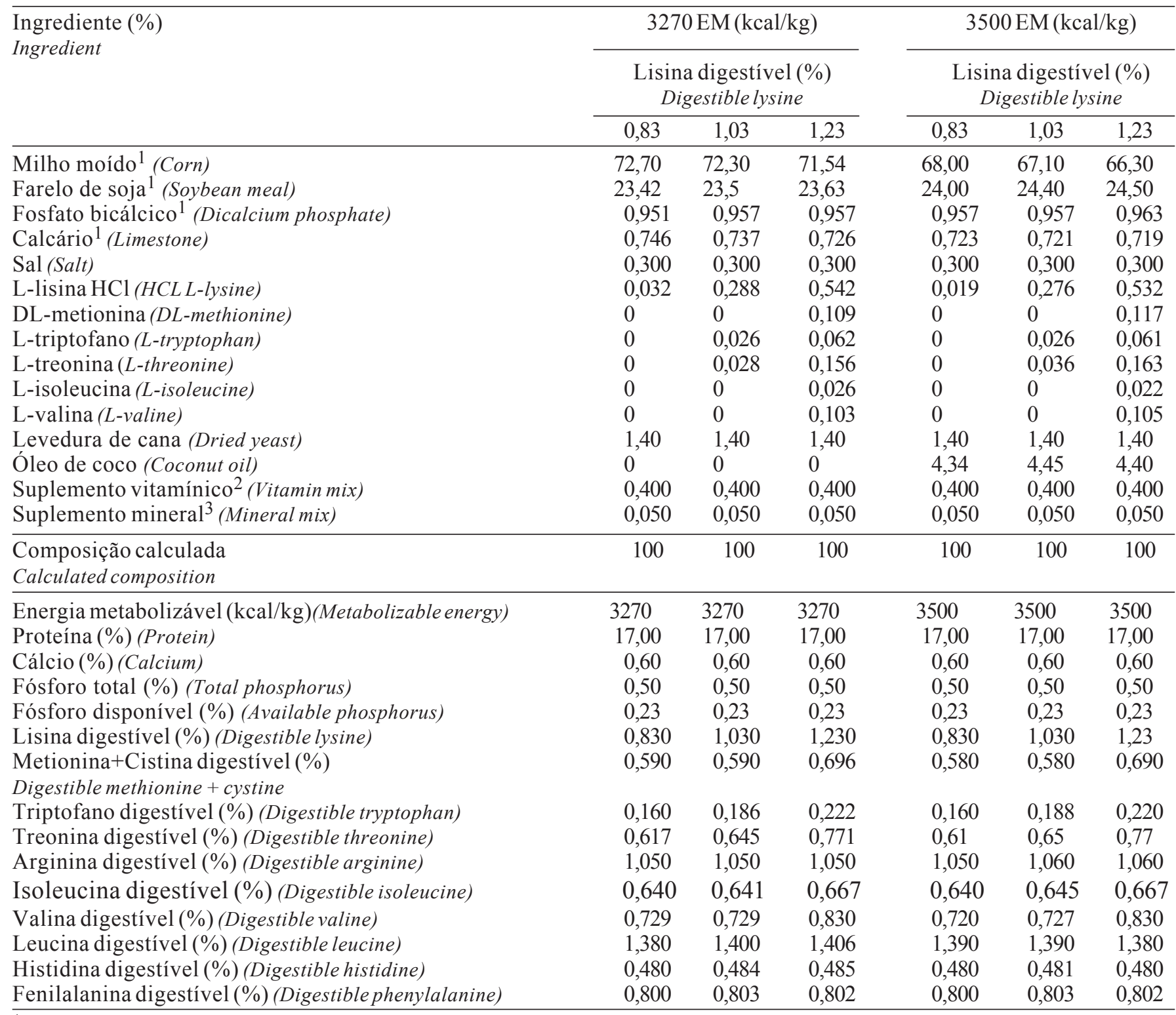

${ }^{1}$ Análise realizada no Laboratório de Bromatologia do CNAA-IZ, segundo Silva (1990) (Analyses were performed at the Bromatologic Laboratory of Instituto de Zootecnia).

2 Fornece/kg de mistura (content/kg): vit. A 1.000 .000 UI, vit. D3 250.000 UI, vit. E 1.812,5 mg, Ác. fólico (Folic acid) 75 mg, Pantotenato de cálcio (Calcium pantotenate) $2000 \mathrm{mg}$, Biotina (Biotin) 6,25 mg, Niacina (niacin) $3.000 \mathrm{mg}$, Piridoxina $250 \mathrm{mg}$, Riboflavina $700 \mathrm{mg}$, Tiamina $250 \mathrm{mg}$, vit. B12 $3750 \mathrm{mcg}$, K3 $125 \mathrm{mg}$, Colina 78,3 g, Promotor de Crescimento e Eficiência alimentar $84.000 \mathrm{mg}$, Antioxidante $30.000 \mathrm{mg}$.

${ }^{3} \mathrm{~kg}$ de mistura (content/kg): Cu 30.000 mg; Zn 160.000 mg; I 1900 mg; Fe 100.000 mg; Mn 70.000 mg, Selênio(Selenium) 75 mg.

de lisina na ração e da ingestão diária do aminoácido. A relação entre ganho de peso e ingestão diária de energia metabolizável (Tabela 3) ratifica essa observação e, ainda que numérica, o ganho/Mcal aumentou em $13,5 \%$ do menor para o maior nível de lisina. Estas evidências não dependeram dos níveis de energia metabolizável empregados no estudo e indicam similaridade às observações de O'Connell (2004) em relação às demandas para ganho de peso e conversão alimentar, ao estabelecerem a melhor relação entre lisina digestível:MJ de energia digestível para suínos dos 40 aos $60 \mathrm{~kg}$. Em situação contrária, quando há excesso de aminoácido, o desempenho poderia ser prejudicado, em razão das implicações metabólicas que envolvem a eliminação desse nutriente, acima das demandas de manutenção e síntese protéica do crescimento, no suíno em condições desejáveis de criação.

Ao converter o consumo de ração para o correspondente em consumo de megacalorias diária (Mcal/ dia), não foi observada interação de nível de lisina e 
energia metabolizável. Houve efeito pronunciado $(\mathrm{P}<0,01)$ para o fator lisina, caracterizando-se resposta quadrática na ingestão de energia, conforme o nível de aminoácido da dieta. Nesse caso, considerado o nível de lisina digestível, a maior ingestão em Mcal/dia ocorreria com $1,00 \%$ do aminoácido na dieta, estimado como ponto ótimo. Na comparação dos níveis de energia metabolizável, as dietas com 3.500 kcal permitiram maior $(\mathrm{P}<0,05)$ ingestão em Mcal/dia pelos machos castrados em crescimento.

$\mathrm{Na}$ estimativa da ingestão diária de lisina, detectou-se interação $(\mathrm{P}<0,01)$ do nível de energia metabolizável e de lisina digestível. Na concentração $3.270 \mathrm{kcal}$ de EM/kg, o aumento da concentração de lisina na dieta correspondeu ao efeito linear ascendente na ingestão do aminoácido $(14,72 ; 19,79$ e 21,24 $\mathrm{g} /$ dia). Resposta semelhante foi observada nas dietas com $3.500 \mathrm{kcal}$ de EM/kg (17,96; 18,70 e 20,86 g/dia). As equações correspondentes a estas respostas en- contram-se na Tabela 3. Quanto ao provável efeito do fator nível de energia sobre a ingestão diária de lisina, não foi observada diferença entre os valores médios obtidos, independentemente da concentração de EM.

Ao estabelecer a relação entre ingestão de lisina digestível por megacaloria de energia metabolizável (lisina: $\mathrm{EM}-\mathrm{g} / \mathrm{Mcal})$, houve interação $(\mathrm{P}<0,01)$ dos fatores energia e lisina. Em quaisquer das concentrações dietéticas de energia, a ingestão de lisina/Mcal teve aumento linear em resposta aos níveis crescentes de lisina na ração. Ao considerar níveis de lisina, dentro de $3.270 \mathrm{kcal} / \mathrm{kg}$ de EM, constatou-se variação $(\mathrm{P}<0,01)$ linear e as relações foram 2,53; 3,15 e 3,76 $\mathrm{g}$ de lisina/Mcal de EM. Do mesmo modo, a resposta para nível de lisina dentro de $3.500 \mathrm{kcal} / \mathrm{kg}$ de EM foi linear ascendente, nas relações 2,90; 2,94 e 3,51 g/ Mcal de EM para os respectivos níveis de lisina digestível empregados nas dietas experimentais. $\mathrm{Na}$ comparação de médias (teste F) das concentrações

Tabela 2 - Desempenho dos machos castrados na fase de crescimento, segundo os níveis de energia e lisina digestível Table 2 - Castrated males performance in the growing phase in response to energy and digestible lysine levels

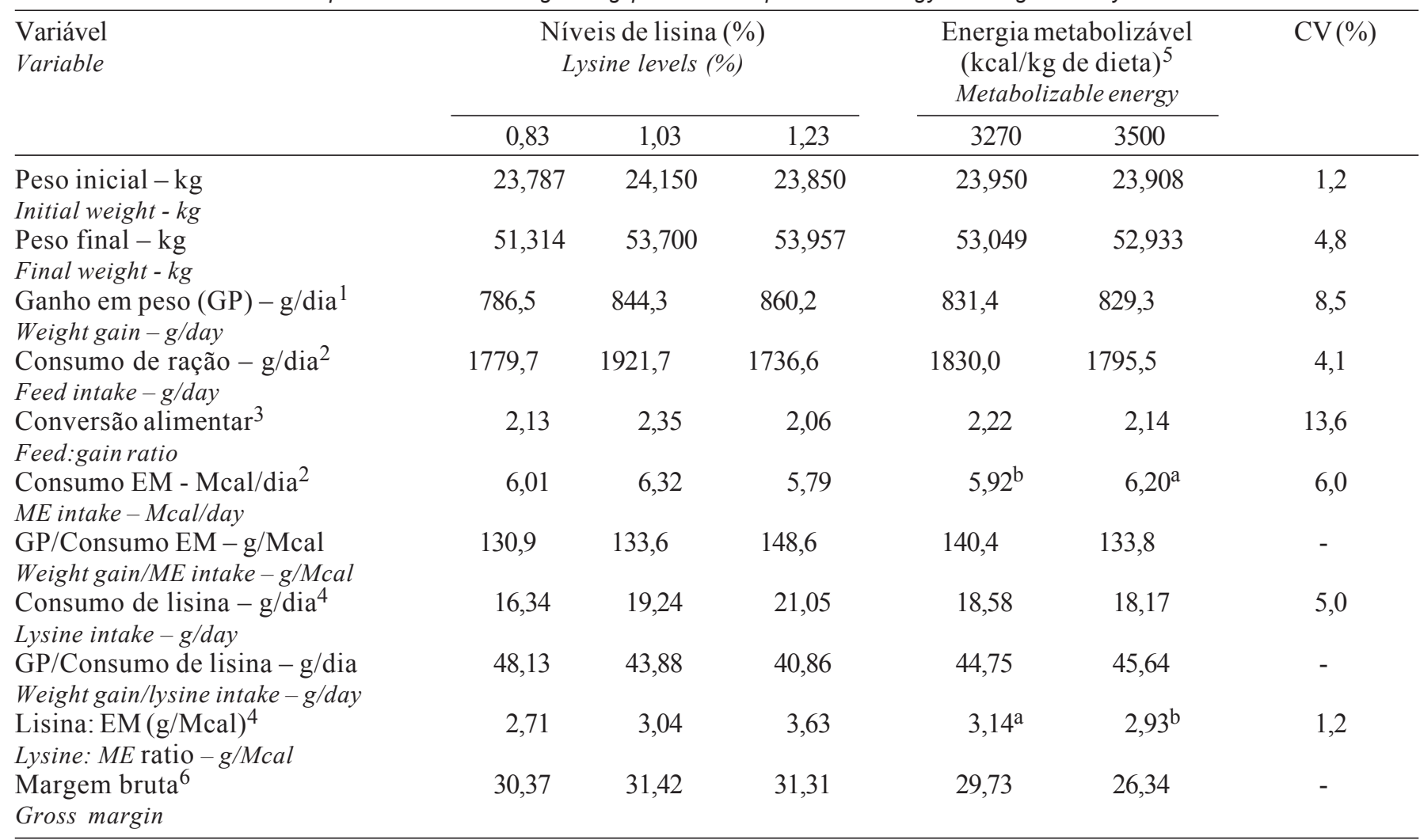

${ }^{1}$ Efeito linear para níveis de lisina $(\mathrm{P}<0,05)$ (Linear effect for lysine levels).

2 Efeito quadrático para níveis de lisina $(P<0,01)$ (Quadratic effect for lysine levels).

${ }^{3}$ Efeito quadrático para níveis de lisina $(\mathrm{P}<0,06)$ (Quadratic effect for lysine levels).

${ }^{4}$ Efeito linear para níveis de lisina $(\mathrm{P}<0,01)$ (Linear effect for lysine levels).

${ }_{5}^{5}$ Médias seguidas de letras diferentes para nível de energia diferem entre si pelo teste $F$, minúsculas $(P<0,03)$ e maiúscula $(P<0,01)$.

${ }^{5}$ Means followed by different letters for energy level differ by $F$ Test, small letter $(P<.03)$ and capital letter $(P<.01)$.

${ }^{6}$ Margem bruta devido à alimentação (gross margin due to the feeding). 
de energia estudadas, a maior $(\mathrm{P}<0,05)$ relação lisina:EM ocorreu no nível $3.270 \mathrm{kcal}$ de EM.

O comportamento linear destes dados indica o aumento da demanda de lisina por calorias ingeridas, durante a fase de maior crescimento e deposição protéica do suíno e ou linhagens cuja seleção é orientada para maior produção de carne e menor deposição de gordura na carcaça. Assim, tender-se-ia confirmar as observações de Van Lunen \& Cole (1996) ao estabelecerem 3,97 g lisina/Mcal de ED (aproximadamente 3,81g/Mcal de EM) como relação ótima para suínos machos castrados dos 25 aos $95 \mathrm{~kg}$.

Os resultados deste estudo indicam relações acima da proposta por Chiba et al. (1991), quando determinaram 3,0 g de lisina/Mcal de ED, cerca de 2,88 g/Mcal de EM, para suínos entre 20 e $50 \mathrm{~kg}$ e obtiveram desempenho máximo, utilizando dietas à base de milho e farelo de soja. Da mesma forma, encontram-se acima dos níveis sugeridos por Castell et al. (1994), Tuitoek et al. (1997) e O'Connell (2004). No primeiro caso, os autores salientaram os benefícios econômicos da relação 2,58 g de lisina/Mcal de ED em dieta para suínos machos castrados dos 25 aos 98 $\mathrm{kg}$. No segundo, concluíram que dietas à base de milho e farelo de soja satisfaziam a relação desejada e as necessidades dos suínos de 20 a $55 \mathrm{~kg}$, aplicando-se o conceito da proteína ideal. E, na terceira situação, sugeriram relação similar para machos castrados e fêmeas, ainda que a primeira categoria apresentasse maior consumo (mais 11\%) e ganho de peso (mais
9\%). Nesse estudo, os autores propuseram a melhor relação em $0,70 \mathrm{~g} / \mathrm{MJ}$ de $\mathrm{EM}$ ou $2,93 \mathrm{~g}$ de lisina digestível/Mcal de EM.

$\mathrm{O}$ aumento linear da ingestão diária de lisina e da relação com a ingestão de energia decorreu do acréscimo da concentração do aminoácido na dieta, embora tenha havido resposta quadrática para consumo de ração. A observação a ser salientada neste estudo com machos castrados se refere à melhoria do ganho de peso e da conversão alimentar, em decorrência do aumento da concentração de lisina digestível na dieta, sem diferenças expressivas para nível de energia metabolizável. Estas respostas caracterizam o aumento da eficiência de utilização dos nutrientes ao elevar o nível do aminoácido e/ou relação de lisina:energia, quando se permite a maior ingestão do aminoácido/kcal.

Outra consideração se refere à maior demanda de lisina, em relação aos demais aminoácidos, nos processos de sínteses afins ao crescimento do suíno, sobretudo em condições desejáveis de saúde. Em específico, os benefícios são creditados ao anabolismo protéico, para formação de massa muscular na carcaça. Considerações dessa ordem são apresentadas por Williams et al. (1997a,b,c), quando concluíram que suínos de 6 a $112 \mathrm{~kg}$, livres dos principais patógenos, foram mais eficientes na taxa de deposição protéica (23\%) e na capacidade de retenção de energia (13\%) em comparação àqueles com títulos para anticorpos de quatro dos principais agentes infecciosos das criações

Tabela 3 - Equações de regressão das variáveis estudadas ao final da fase crescimento com machos castrados Table 3 - Regression equations of the studied variables with castrated males in the final of growing phase

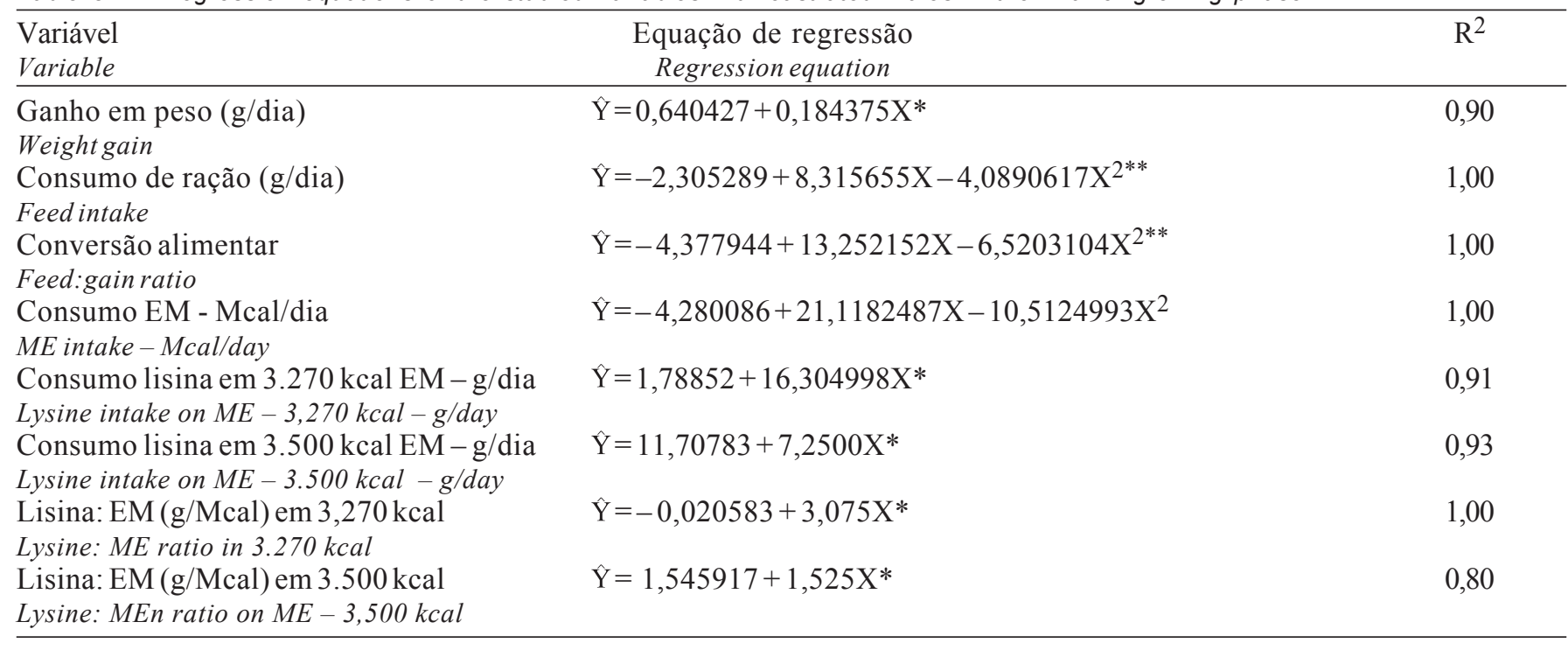

* $(\mathrm{P}<0,05) ;{ }^{* *}(\mathrm{P}<0,01)$. 
em confinamento. Constataram ainda interação das condições imunológicas e dos níveis de lisina, quando os suínos com baixa atividade imunológica responderam mais eficientemente ao aumento das concentrações do aminoácido.

No ensaio com marrãs, cujos resultados são apresentados na Tabela 4, não foi constatada interação dos tratamentos nas variáveis ganho em peso e consumo de ração. Na conversão alimentar, houve efeitos isolados dos fatores principais, constatando-se melhoria linear $(\mathrm{P}<0,001)$, em decorrência do aumento de lisina nas dietas, conforme equação apresentada na Tabela 5 . Quanto à energia metabolizável, os resultados médios indicam que as dietas de $3.500 \mathrm{kcal} / \mathrm{kg}$ propiciaram melhor $(\mathrm{P}<0,04)$ conversão alimentar das marrãs em fase de crescimento, segundo o teste F.

Ao transformar o consumo de ração em ingestão diária de energia metabolizável, confirmou-se a ausência de interação dos fatores e efeitos significativos entre níveis de lisina e energia. Por outro lado, a transformação do consumo de ração em estimativa da ingestão diária de lisina correspondeu à interação $(\mathrm{P}<0,001)$ de nível de energia metabolizável e de lisina digestível. Como era esperado, ao desdobrar a interação, verificou-se que, independentemente da concentração energética da dieta, a ingestão de lisina/ Mcal teve aumento linear quando a concentração dietética do aminoácido foi elevada. As ingestões diárias, correspondentes aos respectivos níveis de lisina $(0,83 ; 1,03$ e $1,23 \%)$ dentro do fator $3.270 \mathrm{kcal}$ de $\mathrm{EM} / \mathrm{kg}$, foram de 14,$72 ; 19,79$ e $21,24 \mathrm{~g}$; e, dentro do fator $3.500 \mathrm{kcal}$ de $\mathrm{EM} / \mathrm{kg}$, de 17,96; 18,70 e 20,86 g/dia, segundo equações apresentadas na Tabela 5 .

Com relação à ingestão diária ascendente de lisina, os resultados tendem à semelhança do nível determinado por Fontes et al. (2000), ao avaliarem níveis de lisina para marrãs de linhagem genética específica. Nesse estudo, sugeriram para animais dos 30 aos $60 \mathrm{~kg}$ ingestão diária de $22,1 \mathrm{~g}$ de lisina, com base na conversão alimentar; não obstante, utilizaram

Tabela 4 - Desempenho das marrãs na fase de crescimento, segundo os níveis de energia e lisina digestível Table 4 - Gilts performance in the growing phase in response to the energy and digestible lysine levels

\begin{tabular}{|c|c|c|c|c|c|c|}
\hline \multirow[t]{2}{*}{$\begin{array}{l}\text { Variável } \\
\text { Variable }\end{array}$} & \multicolumn{3}{|c|}{$\begin{array}{l}\text { Níveis de lisina (\%) } \\
\text { Lysine levels (\%) }\end{array}$} & \multicolumn{2}{|c|}{$\begin{array}{c}\text { Energia metabolizável } \\
{\text { (kcal/kg de dieta })^{2}}^{\text {Metabolizable energy }}\end{array}$} & \multirow[t]{2}{*}{$\mathrm{CV}(\%)$} \\
\hline & 0,83 & 1,03 & 1,23 & 3270 & 3500 & \\
\hline $\begin{array}{l}\text { Peso inicial - } \mathrm{kg} \\
\text { Initial weight }\end{array}$ & 21,960 & 21,250 & 21,480 & 21,966 & 21,160 & 7,2 \\
\hline $\begin{array}{l}\text { Peso final }-\mathrm{kg} \\
\text { Final weight }\end{array}$ & 48,899 & 49,099 & 48,542 & 48,440 & 49,254 & 7,8 \\
\hline $\begin{array}{l}\text { Ganho em peso (GP) - g/dia } \\
\text { Weight gain }\end{array}$ & 769,7 & 795,7 & 773,2 & 756,4 & 802,7 & 14,8 \\
\hline $\begin{array}{l}\text { Consumo de ração - g/dia } \\
\text { Feed intake }\end{array}$ & 1622,8 & 1600,0 & 1551,0 & 1617,0 & 1565,6 & 10,1 \\
\hline $\begin{array}{l}\text { Conversão alimentar }{ }^{1} \\
\text { Feed: gain ratio }\end{array}$ & 2,14 & 2,01 & 1,90 & $2,14^{\mathrm{B}}$ & $1,90^{\mathrm{A}}$ & 10,0 \\
\hline $\begin{array}{l}\text { Consumo EM - Mcal/dia } \\
\text { ME intake - Mcal/day }\end{array}$ & 5,50 & 5,41 & 5,25 & 5,29 & 5,48 & 5,4 \\
\hline $\begin{array}{l}\mathrm{GP} / \text { Consumo EM }-\mathrm{g} / \mathrm{Mcal} \\
\text { Weight gain/ME intake ratio }\end{array}$ & 139,9 & 147,1 & 147,3 & 143,0 & 146,5 & - \\
\hline $\begin{array}{l}\text { Consumo de lisina }-\mathrm{g} / \mathrm{dia}^{1} \\
\text { Lysine intake }\end{array}$ & 3,47 & 16,48 & 19,08 & 16,63 & 16,05 & 9,6 \\
\hline $\begin{array}{l}\mathrm{GP} / \text { Consumo de lisina }-\mathrm{g} / \mathrm{dia} \\
\text { Weight gain/lysine intake ratio }-\mathrm{g} / \text { day }\end{array}$ & 57,14 & 48,28 & 40,52 & 45,48 & 50,01 & - \\
\hline $\begin{array}{l}\text { Lisina: } \mathrm{EM}(\mathrm{g} / \mathrm{Mcal})^{1} \\
\text { Lysine:ME ratio }\end{array}$ & 2,45 & 3,05 & 3,64 & 3,10 & 2,84 & 2,5 \\
\hline $\begin{array}{l}\text { Margem bruta } \\
\text { Gross margin }\end{array}$ & 32,88 & 31,40 & 28,27 & 27,60 & 30,95 & - \\
\hline
\end{tabular}

\footnotetext{
${ }^{1}$ Efeito linear $(P<0,01)$ para níveis de lisina (Linear effect $[P<0.01\}$ for lysine levels).

2 Médias seguidas de letras diferentes para nível de energia diferem $(P<0,01)$ entre si pelo teste $F$.

${ }_{2}^{2}$ Means followed by different letters for energy level differ $(P<0.01)$ by $F$ test.

${ }^{3}$ Margem bruta devido à alimentação (gross margin due to the feeding).
} 
a concentração de $1,19 \%$ do aminoácido digestível o que indica maior consumo de ração, em comparação ao deste estudo.

Quanto às especificidades que envolvem o suíno considerado moderno para os atuais sistemas de produção intensiva, constata-se avanço do melhoramento genético e correspondente aumento nas demandas metabólicas pelos nutrientes dietéticos. Nesse sentido, destacam-se as maiores necessidades da lisina digestível na relação ideal com os demais aminoácidos e os resultados obtidos encontram acima dos propostos, anteriormente. Donzele et al. (1994a,b) propuseram $0,91 \%$ ou $17,7 \mathrm{~g} /$ dia de lisina total para fêmeas dos 30 aos $60 \mathrm{~kg}$. Friesen et al. (1994), utilizando fêmeas entre 34 e $72,5 \mathrm{~kg}$, selecionadas para alta deposição de carne na carcaça, determinaram a exigência mínima de 18 gramas de lisina digestível por dia.

Quando se estabeleceu relação entre ingestão de lisina digestível por megacaloria de energia metabolizável verificou-se interação $(\mathrm{P}<0,01)$ dos fatores energia e lisina. Semelhante à ingestão de lisina, independente da energia na dieta, aumentou-se a ingestão de gramas de lisina/Mcal de EM na medida em que se elevou o nível de lisina dietético. Essa variação $(\mathrm{P}<0,01)$ linear em resposta aos níveis de lisina $(0,85 ; 1,03$ e $1,23 \%)$ caracterizou-se da seguinte forma: nas dietas de $3270 \mathrm{kcal} / \mathrm{kg}$ as relações obtidas de lisina/Mcal de EM foram 2,53; 3,15 e 3,76 g; e naquelas de $3500 \mathrm{kcal} / \mathrm{kg}$ foram 2,90; 2,94 e 3;51 g de lisina/Mcal de EM, respectivamente, conforme equações da Tabela 5. A indicação linear ascendente para essa relação ratifica a necessidade de níveis de lisina acima dos propostos por Chiba et al. (1991) e Castell et al. (1994) que propuseram, respectivamente, 2,88 e 2,58 g lisina/Mcal de EM para o mesmo intervalo de peso do suíno. Castell et al. (1994) enfatizaram a separação de sexo e concluíram que a fêmea necessitaria $2 \%$ a mais de proteína do que machos castrados. Urynek \& Buraczewska et al. (2003) todavia, concluíram que marrãs e machos castrados, com alto ganho em carne, maximizaram a taxa de crescimento com 3,22 g lisina/Mcal de EM.

Uma vez que os ensaios com machos castrados e fêmeas ocorreram simultaneamente, pode-se confirmar observações da literatura quando são relatadas a importância da criação do suíno com a distinção de sexo (Cromwell et al., 1993; Quiniou et al., 1996; Webb, 2003; De Abreu, 2004).

De acordo com Ekstrom (1991), machos castrados consomem mais alimentos e apresentam maior ganho de peso. Ao mesmo tempo, as fêmeas ingerem menos alimentos e são mais eficientes na deposição de carne na carcaça, embora as exigências em aminoácidos possam ser maiores. As respostas para conversão $(\mathrm{P}<0,01)$ neste estudo coadunam estas observações, ratificando a importância da criação com separação por sexo nas fases de maior crescimento.

Confirmando as observações anteriores, fica caracterizada a maior demanda nutricional de lisina e dos demais aminoácidos pelo suíno, respeitada as especificidades, nas condições de segregação sanitária, como sugerido por Stahley (1993), Cromwell et al. (1993) e Susenbeth (1995). Cromwell et al. (1993) destacaram a importância da criação com separação por sexo, tendo-se em vista as vantagens econômicas na produção. Na presente avaliação, o ganho diário de peso por grama de lisina foi em média 44,29 para

Tabela 5 - Equações de regressão das variáveis estudadas com marrãs, ao final da fase crescimento Table 5 - Regression equations of the studied variables with gilts in the final of growing phase

\begin{tabular}{|c|c|c|}
\hline $\begin{array}{l}\text { Variável } \\
\text { Variable }\end{array}$ & $\begin{array}{l}\text { Equação de regressão } \\
\text { Regression equation }\end{array}$ & $\mathrm{R}^{2}$ \\
\hline $\begin{array}{l}\text { Conversão alimentar } \\
\text { Feed:gain ratio }\end{array}$ & $\hat{\mathrm{Y}}=-0,611123+0,2770204 \mathrm{X}$ & 0,85 \\
\hline $\begin{array}{l}\text { Consumo de lisina dentro de } 3.270 \mathrm{kcal} \text { de } \mathrm{EM}-\mathrm{g} / \text { dia } \\
\text { Lysine intake on } M E-3,270 \mathrm{kcal}-\mathrm{g} / \text { day }\end{array}$ & $\hat{\mathrm{Y}}=1,78852+16,304998 \mathrm{X}$ & 0,91 \\
\hline $\begin{array}{l}\text { Consumo de lisina dentro de } 3.500 \mathrm{kcal} \text { de } \mathrm{EM}-\mathrm{g} / \mathrm{dia} \\
\text { Lysine intake on } M E-3,500 \mathrm{kcal}-\mathrm{g} / \text { day }\end{array}$ & $\hat{\mathrm{Y}}=11,70783+7,2500 \mathrm{X}$ & 0,93 \\
\hline $\begin{array}{l}\text { Lisina:EM (g/Mcal) dentro de } 3.500 \mathrm{kcal} \text { de } \mathrm{EM} \\
\text { Lysine: } M E n \text { ratio on } M E-3,500 \mathrm{kcal}\end{array}$ & $\hat{\mathrm{Y}}=1,545917+1,525 \mathrm{X}$ & 0,80 \\
\hline
\end{tabular}


machos castrados e 48,65 para marrãs, indicando maior eficiência das fêmeas na utilização da lisina. Essa variação provavelmente estaria associada ao direcionamento da lisina para a síntese protéica muscular, descrita na literatura como a mais eficaz nas marrãs, comparadas a machos castrados.

No estudo de Cromwell et al. (1993), foram observadas diferenças na eficiência de utilização do alimento para maximização de ganho em carne magra entre machos castrados e marrãs. Adotando novo rigor nesse tipo de avaliação, Friezen et al. (1996) concluíram que, além do ganho e da conversão, as taxas de deposição na carcaça permitiriam aproximação mais eficiente na caracterização das respostas para níveis de lisina digestível da dieta, durante o crescimento.

O ganho de peso e a conversão alimentar obtidos, respectivamente, com machos castrados e marrãs na fase de crescimento são indicativos da necessidade constante no ajuste das exigências nutricionais, devendo-se ater às especificidades do suíno selecionado para produção de carne. Considerações foram feitas por Rao \& McCracken (1990) com relação à necessidade de reavaliações da eficiência de utilização da proteína (aminoácidos) com suínos selecionados para altas taxas de ganho e deposição de carne magra, ao observarem que animais com alto potencial de desempenho muscular apresentaram maior acúmulo protéico dos 20 aos $50 \mathrm{~kg}$, enquanto Chavez (1996) observou que, em animais com menor potencial de desempenho, a deposição protéica foi quase constante dos 40 aos $90 \mathrm{~kg}$ de peso vivo.

No mesmo nível de importância, atenção deve ser dada para a criação comercial de suínos com separação de sexos e a condição do ambiente imposta a esse animal, quando submetido ao sistema intensivo de produção. Nesse sentido, informações da literatura confirmam que, ao se estabelecer desafios adicionais ao sistema imunológico, haverá implicações negativas no que se espera do desempenho para o crescimento e o incremento de massa muscular. Desse modo, devem ser entendidas as ações no melhoramento genético e na nutrição do suíno, na busca do sucesso e validação da seleção desses caracteres considerados de média e alta herdabilidade.

A partir da determinação da margem bruta em função da alimentação (Tabelas 2 e 4), a dieta com $1,03 \%$ de lisina digestível seria a mais indicada para as duas categorias de suíno, enquanto dieta com $3.270 \mathrm{kcal}$ seria a mais indicada para machos castrados e com
$3.500 \mathrm{kcal}$ de energia metabolizável, a mais indicada para marrãs.

A viabilidade econômica no emprego dos níveis nutricionais propostos depende dos preços para aquisição dos principais ingredientes da ração e do preço pago pelo suíno.

\section{Conclusões}

Criados com separação de sexo e em condições desejáveis de saúde, na fase de crescimento, suínos machos castrados e marrãs da linhagem genética estudada respondem eficientemente ao acréscimo de lisina digestível nas dietas.

Os benefícios dietéticos da lisina no desempenho dos machos castrados não dependeram dos níveis de energia estudados.

O aumento da concentração de lisina digestível e de energia metabolizável $(3.500 \mathrm{kcal} / \mathrm{kg})$ na dieta propicia maior eficiência de utilização da energia pelas marrãs.

\section{Agradecimento}

\section{À FAPESP e à AJINOMOTO BIOLATINA,} pelo apoio.

\section{Literatura Citada}

AFFENTRANGER, P.; GERWIG, C.; SEEWER, G.J. et al. Growth and carcass characteristics as well as meat and fat quality of three types of pigs under different feeding regimens. Livestock Production Science, v.45, n.2/3, p.187-96, 1996.

BATTERHAM, E.S. Protein and energy relationships for growing pigs. In: COLE, D.J.A.; WISEMAN, J.; VARLEY, M.A. (Eds.) Priciples of pig science. Nottinghan: Redwood Books, 1994. p.107-21.

CASTELL, A.G.; CLIPLEF, R.L.; POSTEFLYNN, L.M. et al. Performance, carcass and pork characteristics of castrates and gilts self-fed diets differing in protein-content and lysineenergy ratio. Canadian Journal of Animal Science, v.74, n.3, p.519-528, 1994.

CHAVEZ, E.R. Requerimientos nutricionales y alimentación de los genotipos modernos de cerdos de carne magra. In: SEMINARIO INTERNACIONAL DE PORCICULTURA, 4., 1996, Lima. Anais... Lima: 1996. p.59-76.

CHIBA, L.I.; LEWIS, A.J.; PEO JR., E.R. Amino acid and energy interrelationships in pigs weighing 20 to 50 kilograms: I. Rate and efficiency of weight gain. Journal of Animal Science, v.69, n.2, p.694-707, 1991

CLAUS, R.; WEILER, U. Endocrine regulation of growth and metabolism in the pig: a review. Livestock Production Science, v.37, n.3, p.245-60, 1994.

CROMWELL, G.L.; CLINE, T.R.; CRENSHAW, J.D. et al. The dietary protein and (or) lysine requirements of barrows and gilts. Journal of Animal Science, v.71, n.6, p.1510-1519, 1993. 
DE ABREU, M.L.T.; DONZELE, J.L.; ROSTAGNO, H.S. Atualização das exigências nutricionais de suínos em crescimento. In: CONGRESSO LATINO AMERICANO DE SUINOCULTURA, 2., 2004, Foz do Iguaçu. Anais ... Foz do Iguaçu: Animalworld, 2004. p.145-151.

DONZELE, J.L.; FREITAS, R.T.F.; OLIVEIRA, R.F.M. et al. Níveis de lisina para leitoas de 30 a $60 \mathrm{~kg}$ de peso vivo. Revista Brasileira de Zootecnia, v.23, n.6, p.967-973, 1994a.

DONZELE, J.L.; FREITAS, R.T.F.; OLIVEIRA, R.F.M. et al. Níveis de lisina para marrãs dos 60 aos $100 \mathrm{~kg}$ de peso vivo. Revista Brasileira de Zootecnia, v.23, n.6, p.959-966, 1994 b.

DOURMAD, J.Y.; GUILLOU, D.; SÈVE, B. et al. Response to dietary lysine supply during the finishing period in pigs, Livestock Production Science, v.45, n.2/3, p.179-186, 1996.

EKSTROM, K.E. Genetic and sex considerations in swine nutrition. In: MILLER, E.R.; ULLREY, D.E.; LEWIS, A.J. (Eds.) Swine nutrition. Stonehan: British Library, 1991. p.415-424.

ETTLE, T.; ROTH-MAIER, D.A.; ROTH, F.X. Effect of apparent ileal digestible lysine to energy ratio on performance of finishing pigs at different dietary metabolizable energy levels. Journal of Animal Physiology and Animal Nutrition, v.87, n.7-8, p.269-279, 2003.

EWAN, R.C. Energy utilization in swine nutrition. In: MILLER, E.R.; ULLREY, D.E.; LEWIS, A.J. (Eds.) Swine nutrition, 1.ed. Stonehan: Butterworth-Heinemann, 1991. p.121-132.

FONTES, D.O.; DONZELE, J.L.; OLIVEIRA, R.F.M. et al. Níveis de lisina para leitoas selecionadas geneticamente para deposição de carne magra, dos 30 aos $60 \mathrm{~kg}$, mantendo constante a relação entre lisina e metionina+cistina, treonina, triptofano, isoleucina e valina. Revista Brasileira de Zootecnia, v.29, n.3, p.776-783, 2000.

FRIESEN, K.G.; NELSSEN, J.L.; GOODBAND, R.D. et al. Influence of dietary lysine on growth and carcass composition of higth-lean growth gilts fed from 34 to 72 kilograms. Journal of Animal Science, v.72, n.7, p.1761-1770, 1994.

FRIESEN, K.G.; NELSSEN, J.L.; GOODBAND, R.D. et al. The use of compositional growth curves for assessing the response to dietary lysine by high-lean growth gilts. Animal Science, v.62, n.1, p.159-169, 1996.

FULLER, M.; WANG, T.C. Digestible ideal protein - a measure of dietary protein value. Pig News Information, v.11, n.3, p.353-357, 1990.

GUIDONI, A.L.; ZANOTTO, D.L.; BELLAVER, C. Método alternativo na análise bioeconômica de experimentos com alimentação de suínos. In: REUNIÃO ANUAL DA SOCIEDADE BRASILEIRA DE ZOOTECNIA, 34., 1997, Juiz de Fora. Anais... Juiz de Fora: Sociedade Brasileira de Zootecnia, 1997. p.106-108.

KOLSTAD, K.; VANGEN, O. Breed differences in maintenance requirements of growing pigs when accouting for changes in body composition. Livestock Production Science, v.47, n.1, p.23-32, 1996.

NATIONAL RESEARCH COUNCIL - NRC. Nutrient requirement of swine. 10.ed. Washington, D.C.: National Academy of Sciences, 1998. 189p.

O'CONNELL, K. Response of growing-finishing pigs to lysine in the diet. http://www.teagasc.ie/publications/2004/ 20041011/paper08.htm
PATIENCE, J.F.; THACKER, P.A.; LANGE, C.F.M. Swine nutrition guide. 2.ed. Saskatoon: Prairie Swine Centre Inc. 1995. 274p.

QUINIOU, N.; NOBLET, J.; DOURMAD, J.Y. Effect of energy intake on the performance of different types of pig from 45 to $100 \mathrm{~kg}$ body weight. 2. Tissue gain. Animal Science, v.63, n.2, p.289-96, 1996.

RAO, D.S.; McCRACKEN, K.J. Effect of protein intake on energy and nitrogen balance and chemical composition of gain in growing boars of high genetic potential. Animal Production, v.51, n.3, p.389-397, 1990.

STATISTICAL ANALYSES SYSTEM - SAS. SAS User's guide: statistics. Version 6.12. Cary: 1996.

SILVA, D.J. Análise de alimentos: métodos químicos e biológicos. 2.ed. Viçosa, MG: Universidade Federal de Viçosa, 1990. $59 \mathrm{p}$.

STAHLEY, T. Nutrition affects lean growth, carcass composition. Feedstuffs, v.65, n.26, p.12/23, 1993.

SUSENBETH, A. Factors affecting lysine utilization in growing pigs: an analysis of literature data. Livestock Production Science, v.43, n.3, p.193-204, 1995.

TUITOEK, J.K.; YOUNG, L.G.; LANGE, C.F.M. et al. Body composition and protein and fat accretion in various body components in growing gilts fed diets with different protein levels but estimated to contain similar levels of ideal protein. Journal of Animal Science, v.75, n.6, p.1584-90, 1997.

URYNEK, W.; BURACZEWSKA, L. Effect of dietary energy concentration and apparent ileal digestible lysine: metabolisable energy ratio on nitrogen balance and growth performance of young pigs. Journal of Animal Science, v.81, n., p.1227-36, 2003.

VAN LUNEN, T. A.; COLE, D.J.A. The effect of lysine/digestible energy ratio on growth performance and nitrogen deposition of hybrid boars, gilts and castrated male pigs. Animal Science, v.63, n.3, p.465-475, 1996.

WEBB, J. How we produce a uniform high quality market pig. In: LONDON SWINE CONFERENCE, 2003, London, Proceedings... London, 2003. p.105-111. httpwww.londonswineconference.ca-proceedings-2003LSC2003_JWebb.pdf

WILLIAMS, N.H.; STAHLY, T.S.; ZIMMERMAN, D.R. Effect of chronic immune system activation on body nitrogen retention, partial efficiency of lysine utilization, and lysine needs of pigs. Journal of Animal Science, v.75, n.9, p.24722480, 1997a.

WILLIAMS, N.H.; STAHLY, T.S.; ZIMMERMAN, D.R. Effect of chronic immune system activation on the rate, efficiency, and composition of growth and lysine needs of pigs fed from 6 to $27 \mathrm{~kg}$. Journal of Animal Science, v.75, n.9, p.2463-2471, $1997 \mathrm{~b}$.

WILLIAMS, N.H.; STAHLY, T.S.; ZIMMERMAN, D.R. Effect of chronic immune system activation on the growth and dietary lysine needs of pigs fed from 6 to $112 \mathrm{~kg}$. Journal of Animal Science, v.75, n.9, p.2481-2496, 1997 c.

Recebido em: 13/09/04 Aceito em: 26/04/05 